\title{
Use of Health Information Exchange in The Continuity of Care as Viewed by Patients and Nurses: A Cross Sectional Study
}

Michal Itzhaki ( $\square$ itzhakim@tauex.tau.ac.il )

Tel Aviv University School of Medicine https://orcid.org/0000-0002-5182-403X

Ella Koren

Sheba School of Nursing: Ziva Tal Academic School of Nursing

Khaled Abu Hussien

Maccabi Healthcare Services

Liron Levy

Maccabi Healthcare Services

Irit Gantz

Meir Medical Center School of Nursing

Sivia Barnoy

Tel Aviv University Department of Nursing

Research article

Keywords: Contact nurses, Health information exchange, Medical data, Nurses Patients

Posted Date: September 15th, 2020

DOI: https://doi.org/10.21203/rs.3.rs-72163/v1

License: (c) (i) This work is licensed under a Creative Commons Attribution 4.0 International License. Read Full License

Version of Record: A version of this preprint was published at CIN: Computers, Informatics, Nursing on March 30th, 2022. See the published version at https://doi.org/10.1097/CIN.0000000000000861. 


\section{Abstract}

Background: Patients' attitudes towards sharing their personal health information are critical for implementation of Health Information Exchange (HIE). Nurses contribute significantly to information sharing within the care continuum in hospitals and community. The purpose of this study was to examine the awareness and readiness of chronic ill patients and nurses to use HIE.

Methods: A cross sectional study among 312 inpatients with a chronic illness, 110 nurses working in internal wards, and 55 contact nurses working in a large Health Maintenance Organization. Multiple linear regressions were performed to assess the associations between knowledge, attitudes, sociodemographics, and both the readiness and intention to use HIE.

Results: Mean levels of awareness were low across all three groups. The readiness to share information with medical healthcare providers was higher than the readiness to share information with agents not involved in direct care. Contact nurses expressed more positive attitudes than internal ward nurses or patients $(F=11.25 ; p=.0001)$ and were more willing than patients to share information with health care workers $(F=16.786 ; p=0001)$. All nurses (Internal ward and contact) were more willing to share information with medical agents not involved in direct care as compared to patients $(F=8.072 ; p=.0001)$. Contact nurses expressed a significantly greater intention to use HIE than did internal ward nurses or patients ( $F=9.825 ; p=.0001)$, Knowledge, attitudes and being a nurse predicted the intention to share information on HIE with medical health care providers $(F=29.91)$, and with agents not involved in direct care $(\mathrm{F}=19.65)$.

Conclusions: Before implementation of an HIE system, it is important to raise awareness, readiness, and intention to use HIE among the general public, nurses, and other medical staff. Policy makers should organize national campaigns under the auspices of the Ministry of Health, in order to present the advantages of HIE and provide detailed information about the systems.

\section{Introduction}

Health information exchange (HIE) is the sharing of medical data between various medical practitioners and organizations [1]. The information available in HIE can facilitate consistent treatment, improve patient safety, reduce care-related costs, and prevent medical errors in diagnosis and treatment [2-3]. HIE systems are complex and may have unpredictable outcomes, both negative and positive. Disadvantages of employing HIE include privacy issues, protection of personal data, and the need for personnel training. Over the last decade, the number of operational HIE organizations has risen steadily and medical institutions' participation in HIEs has grown [4]. However, despite the global increase in HIE, its use is still limited. Among the barriers that delay the implementation of HIE are concerns about compromising patient privacy and security, the risk of initiating a train of errors, lack of appropriate training to use HIE, personnel resistance to change, difficulties with information technology, and a lack of adequate financial resources [5-6]. Moreover, a systematic review revealed that the most common obstacles to HIE use are 
the failure of organizations to integrate HIE into the workflow, and missing data. Interestingly, the use of HIE by non-physicians, such as nurses, may be more extensive [7].

A number of national governments are currently diverting substantial resources towards promoting the adoption of HIE [7]. Indeed, a systematic review revealed that the use of HIE in developed countries is increasing slowly over time [5]. In the USA, the Health Information Technology for Economics and Clinical Health (HITECH) Act of 2009 allocated financial incentives to encourage the establishment of HIE in medical institutions. Despite these measures, the level of HIE adoption by hospitals in a selection of developed countries remains generally low to moderate [8]. Similarly, the level of HIE implementation was only moderate in 27 European Union countries, and other countries such as Turkey, Iceland and Croatia [9].

\section{Background}

On January 29, 2014, the Israeli Ministry of Health published an administrative circular, describing a national computerized HIE project to which the health organizations would be able to connect digitally in order to share information [10]. Due to inconsistencies with the Health Insurance Law, this circular was cancelled a short time after its publication. However, all the aspects of the circular are included in a national digital health project named "Eitan", recently announced by the Israeli Ministry of Health [11], whereby all the medical files of Israeli citizens will be combined in a single database. "Eitan" is a closed and secured communication network that will allow information to be shared and transferred between hospitals and Health Maintenance Organizations (HMOs); In Israel healthcare services are public and provided to all citizens by four HMOs. This project includes developing applications, deploying the system in information sharing sites, and mapping the terminology of sites in fields such as laboratory results and diagnosis according to regulated catalog values. The terms in the database will be coded by health professionals including physicians, nurses, pharmacists, and lab workers [12].

The Ministry of Health [11] guidelines provide access to the data only to healthcare workers in hospitals by personal authorization. This access will be limited to patient's medical information during hospitalization, where the hospitalization data will include HMO-derived health information from the patient's medical records. To ensure security, specific authorization for access to the network will be given to the hospital teams involved in the patient's direct care. Permission holders are granted access to the network during the patient's hospitalization and for a specified period of time thereafter. The HMOs will receive medical summaries of patient's hospital visits for all insured members on the day of discharge. The information will later be integrated into the medical records in the HMOs. The "Eitan" system will not include sensitive information such as records of psychiatric treatment in units and clinics, pregnancy termination, laboratory results of HIV testing, genetic testing and counselling, surrogacy and adoption, egg and sperm donation, or treatment of sexual assault victims. All Israeli citizens will be provided with the option to be excluded from the HIE [11]. 
Currently, until the project is fully implemented, continuity of care between hospitalization and the community in Israel is mediated through contact nurses who coordinate the continuation of treatment after hospital discharge. Contact nurses are community nurses who have access to HMO medical information but not to the hospitalization data, except for the hospital discharge letter. Similarly, while the patient is in hospital, medical information from the community clinic may be lacking, forcing the staff to rely on patient self-reporting rather than on medical records.

Patients' attitudes towards sharing their personal health information are critical for future implementation of HIE, however this aspect has been rarely examined. As a result of the current efforts made by HIE policy makers in the USA to increase public awareness, the USA is responsible for the few publications that have considered a patient's perceptions of the HIE. ${ }^{13}$ Medford-Davis et al found that the majority of 982 sampled patients in Emergency departments in the USA were willing to share their medical information although they retained reservations about privacy and security [14]. About half the sample required a signed declaration concerning the identity of people having access to their health records, and were not in favor of automatic sharing. While health care teams are the primary users of HIE systems, only a few studies have examined their attitudes towards HIE and their intention to use it [7]. Wright et al found positive attitudes to HIE among 1043 physicians in Massachusetts, where 70\% thought the use would reduce healthcare costs, $86 \%$ believed it would improve the treatment quality, and $76 \%$ said it would save time. It should be noted however, that $71 \%$ expressed concerns about the privacy of patients' data [15].

It seems logical that nurses should be fully involved in planning, implementing, and evaluating HIE systems since they play a key role in acquiring patients' health information in the hospital and community. However, a study conducted in the United States on nurses in emergency departments found that even when there was a system of computerized medical information sharing, in many cases, nurses failed to use it because of lack of access [3]. When nurses did have full access to HIE, they used it more often than physicians. The study results indicated that $18.5 \%$ of nurses tended to use HIE compared with only $7.7 \%$ of physicians. In addition, more nurses than physicians ( $48.3 \%$ vs. $9.4 \%)$ used the system to obtain integrated information (clinical and demographic) about patients. Out of all the healthcare workers, pharmacists were the largest group (83.9\%) to use a HIE system [16].

Since nurses contribute significantly to information sharing within the care continuum in hospitals and community and strongly influence patient readiness with regard to information sharing, it is important to examine their attitudes and those of patients regarding HIE in the continuity of care. The aim of this study was to examine the attitudes of hospital and community nurses as well as patients towards computerized HIE and assess their intention to use such a system.

\section{Methods}

\section{Study design}




\section{Data collection}

Data were collected using a questionnaire consisting of four parts. The questionnaire had two versions with content that differed only in the background data section, where one was addressed to patients and the second to nurses (see Supplementary material: Questionnaire for patients and nurses). The required sample size was obtained by means of the $G^{*}$ power program [17]. The sample size required for achieving power of 0.90 and a of .05 was 138 participants in each of the two groups nurses and patients. Data were collected from a convenience sample consisting of 482 participants. Inclusion criteria for patients was having a chronic disease that was treated by their general physician in the community, being hospitalized for at least 48 hours and being fluent in Hebrew. The sampled population included 312 inpatients with a chronic illness who were hospitalized in internal medicine departments of two hospitals in central Israel, and 110 nurses working in these departments. An additional 55 contact nurses working in a large HMO were also included.

\section{Research Tool}

The first part of the survey examined the background variables of the participants, including age, gender, marital status, education, and degree of religiosity. In addition, the questionnaire designed for the nurses included questions about job position, seniority in nursing, and professional education. Two additional items addressed the awareness of the intention to implement HIE in Israel and queried the source of this knowledge. The second part of the questionnaire examined knowledge, attitudes, readiness to use $\mathrm{HIE}$, and intention to use the system.

Knowledge was measured by 19 items examining knowledge about computerized HIE. The construction of this section was based on the literature [15,18] and the Ministry of Health administrative circular [10]. The questionnaire presented items that examined knowledge regarding the operation of and the domains to be included in the HIE. Participants were asked to indicate whether each item was correct or incorrect, or to record that they did not know the answer. The sum of the correct answers was calculated, with a higher score indicating a higher level of knowledge. The possible scores ranged between 0-19.

Attitudes towards the HIE. The construction of this part was based on the literature $[2,3,16]$. and on a validated tool that examines attitudes towards HIE [18]. The questionnaire was face validated by four head nurses working either in internal wards or at an HMO. The judges were asked to indicate whether the items in the questionnaire examined attitudes towards HIE. Only items approved by all the judges were included in the questionnaire. The final questionnaire included 12 statements examining attitudes towards the impact of the HIE on treatment. For each statement, the participants were asked to indicate their agreement on a five point scale ranging from 1 (do not agree at all) to 5 (completely agree). An average score of all items was calculated. Cronbach's Alpha of the scale was 0.849 . 
Readiness to share medical information through HIE. In this part, the respondents were asked to indicate their readiness to share their medical information through HIE with a list of 14 medical and medical agents not involved in direct care. This list was compiled according to the guidelines of the Israeli Ministry of Health [10]. Factor analysis using Varimax rotation revealed two constructs. The first was a readiness to share personal medical information with medical healthcare providers represented by seven agents: community clinics, other hospitals, private physicians, physicians from a different hospital, clinic nurses, nurses from another hospital, and other health professionals (physical therapist, social worker occupation therapist, dietitians). The second was a readiness to share personal medical information with medical agents not involved in direct care. These were represented by eight agents, including psychologists, pharmacists, genetic counsellors, risk management units at the hospital, laboratory managers, and medical researchers. The Cronbach's Alpha of the first construct was 0.887 , and of the second, 0.865 .

Intention to use HIE. At the end of the questionnaire, there was one general question asking nurses how much they would use the computerized HIE and the patients to what extent they agreed that information about them could be used as part of the HIE. This was answered on a scale of 1 (not at all) to 10 (absolute agreement).

\section{Procedure}

Prior to data collection, the research team held meetings with the departmental managers and head nurses to explain the purpose of the research. All participants gave their approval to the research. In the internal wards, questionnaires were distributed by four research assistants to patients with chronic diseases hospitalized for at least 48 hours and to nurses working on the same wards. In the HMO, questionnaires were distributed by email to contact nurses who work as nurse coordinators between hospitalized patients and the community. Before completing the questionnaire, participants received a brief explanation of the study objectives. The research assistants were available to answer questions and collected the completed questionnaires.

\section{Data Analysis}

Data were analyzed using IBM® SPSS ${ }^{\circledR}$ English version 25.0 software (SPSS Inc., Chicago, IL, USA). Participants' characteristics were presented using means and frequencies. Differences between the groups were analyzed using one way analysis of variance (ANOVA). Scheffe tests were performed post hoc in order to reveal the source of any differences. Multiple linear regressions were performed to assess the associations between knowledge, attitudes, and socio-demographics, and both the readiness to share information on HIE, and intention to use HIE. Factor analysis with Varimax rotation was performed to confirm clusters of agents with whom there was a readiness to share personal medical information on HIE. 


\section{Results}

The research sample consisted of a total of 482 participants, comprising 312 inpatients living with a chronic disease (diabetes, heart disease, hypertension) and hospitalized in internal wards, 115 nurses working on these wards, and 55 contact nurses working in a large HMO. The demographic characteristics of the participants are presented in Table 1. The results indicated that most of the participants (nurses or patients) were unaware of HIE. 
Table 1

Socio-demographic characteristics of the sample $(n=482)$

\begin{tabular}{|c|c|c|c|}
\hline & \multicolumn{3}{|c|}{ Category of Responder } \\
\hline & Contact Nurses & Hospital Nurses & Patients \\
\hline & $\mathrm{N}(\%)$ & $\mathrm{N}(\%)$ & $\mathrm{N}(\%)$ \\
\hline Gender & $(N=54)$ & $(N=110)$ & $(N=311)$ \\
\hline Male & $2(3.7$ & $29(26.4)$ & $170(54.7)$ \\
\hline Female & $52(96.3)$ & $81(73.6)$ & $141(45.3)$ \\
\hline Place of Birth & $(N=55)$ & $(N=110)$ & $(N=312)$ \\
\hline Israel & $32(58.2)$ & $78(70.9)$ & $177(56.7)$ \\
\hline Former USSR & $15(27.3)$ & $25(27.3)$ & $42(13.5)$ \\
\hline Other & $8(14.5)$ & $7(6.4)$ & $93(29.8)$ \\
\hline Education & $(N=55)$ & $(N=108)$ & $(N=291)$ \\
\hline Elementary School & 0 & 0 & $18(6.2)$ \\
\hline High School & 0 & 0 & $115(39.5)$ \\
\hline Tertiary Education & $5(9.3)$ & $20(18.5)$ & $63(21.6)$ \\
\hline Academic & $50(90.7)$ & $88(81.5)$ & $95(32.6)$ \\
\hline Marital Status & $(\mathrm{N}=55)$ & $(N=108)$ & $(\mathrm{N}=303)$ \\
\hline Single & $5(9.1)$ & $34(31.5)$ & $25(8.3)$ \\
\hline Married, living with partner & $44(80.0)$ & $70(64.8)$ & $179(59.1)$ \\
\hline Divorced & $5(9.1)$ & $4(3.7)$ & 40 (13.2) \\
\hline Widow/Widower & $1(1.8)$ & 0 & $59(19.5)$ \\
\hline Religion & $(N=55)$ & $(\mathrm{N}=115)$ & $(\mathrm{N}=312)$ \\
\hline Jewish & $49(89.1)$ & $67(61.5)$ & $295(94.6)$ \\
\hline Muslim & $4(7.3)$ & $38(34.9)$ & $4(1.3)$ \\
\hline Christian & $1(1.8)$ & $7(0.9)$ & $7(2.2)$ \\
\hline Other & $1(1.8)$ & $3(2.8)$ & $6(1.9)$ \\
\hline Awareness about HIE & $(N=54)$ & $(N=109)$ & $(N=311)$ \\
\hline
\end{tabular}




\begin{tabular}{|llll|}
\hline \multicolumn{4}{|c|}{ Category of Responder } \\
\hline Yes & $18(33.3)$ & $22(20.6)$ & $28(9.0)$ \\
\hline No & $36(66.7)$ & $85(79.4)$ & $283(91.0)$ \\
\hline Age (Mean (SD)) & $45.7(9.89)$ & $33.3(8.02)$ & $63.5(16.77)$ \\
\hline Religiosity (scale of 1-10) & $2.8(2.62)$ & $4.6(2.79)$ & $5.06(2.88)$ \\
\hline SD = standard deviation & & & \\
\hline
\end{tabular}

One-way ANOVA tests were used in order to compare the mean levels of knowledge, about HIE, attitudes towards HIE, readiness to share information via the HIE and intention to share information on HIE, of the three groups (contact nurses, internal ward nurses, and patients). The results are presented in Table 2.

Table 2

One-way ANOVA, comparison of study variables between contact nurses, hospital nurses, and patients

\begin{tabular}{|c|c|c|c|c|c|}
\hline & \multicolumn{5}{|c|}{ Responder Categories } \\
\hline & $\begin{array}{l}\text { Contact } \\
\text { Nurses }\end{array}$ & $\begin{array}{l}\text { Hospital } \\
\text { Nurses }\end{array}$ & Patients & $F(2,478)$ & \\
\hline Knowledge about HIE & $\begin{array}{l}7.95 \\
(4.39)\end{array}$ & $\begin{array}{l}7.07 \\
(4.02)\end{array}$ & $\begin{array}{l}7.36 \\
(3.40)\end{array}$ & $\begin{array}{l}1.03 ; P \\
=.356\end{array}$ & $\begin{array}{l}a= \\
b= \\
c\end{array}$ \\
\hline Attitudes towards HIE & $\begin{array}{l}4.19 \\
(0.41)\end{array}$ & $\begin{array}{l}3.71 \\
(0.61)\end{array}$ & $\begin{array}{l}3.86 \\
(0.63)\end{array}$ & $\begin{array}{l}\text { 11.25; } \\
P \\
=.0001\end{array}$ & $\begin{array}{l}\text { a }> \\
\text { b.c }\end{array}$ \\
\hline $\begin{array}{l}\text { Readiness to share information with health } \\
\text { care workers }\end{array}$ & $\begin{array}{l}4.16 \\
(0.61)\end{array}$ & $\begin{array}{l}3.69 \\
(0.81)\end{array}$ & $\begin{array}{l}3.36 \\
(1.12)\end{array}$ & $\begin{array}{l}\text { 16.786; } \\
P \\
=.0001\end{array}$ & $\begin{array}{l}a> \\
b, c\end{array}$ \\
\hline $\begin{array}{l}\text { Readiness to share information with medical } \\
\text { agents not involved in direct care }\end{array}$ & $\begin{array}{l}2.92 \\
(0.87)\end{array}$ & $\begin{array}{l}2.85 \\
(0.93)\end{array}$ & $\begin{array}{l}2.46 \\
(1.15)\end{array}$ & $\begin{array}{l}8.072 ; P \\
=.0001\end{array}$ & $\begin{array}{l}a, b \\
>c\end{array}$ \\
\hline Intention to share information on HIE & $\begin{array}{l}8.75 \\
(1.31)\end{array}$ & $\begin{array}{l}7.24 \\
(2.16)\end{array}$ & $\begin{array}{l}7.00 \\
(2.98)\end{array}$ & $\begin{array}{l}9.825, P \\
=.0001\end{array}$ & $\begin{array}{l}a> \\
b, c\end{array}$ \\
\hline
\end{tabular}

The level of knowledge was generally similar and rather low in all three groups, with no significant differences. As presented in Table 2, the results indicated that the attitudes of the three groups towards $\mathrm{HIE}$ were quite positive (above average). The difference between the groups was significant $(\mathrm{F}=11.25 ; P$ 
$<.001)$. A post hoc Scheffe test revealed that the source of the difference was that contact nurses held significantly more positive attitudes towards HIE than either internal ward nurses or patients.

The results also indicated a relatively high degree (above average) of readiness to share personal medical information via HIE with medical healthcare providers. A comparison showed a significant difference between the readiness of the three groups to share information $(F=16.78 ; P<.001)$. A post hoc Scheffe test revealed that the source of the difference was that contact nurses were significantly more willing to share personal medical information with healthcare workers through HIE than internal ward nurses or patients.

The readiness to share personal medical information through HIE with medical agents not involved in direct care was rather low in all the groups although the differences between the groups were significant $(F=8.07 ; P<.001)$. The results of a post hoc Scheffe test showed that the source of the difference was that the two groups of nurses were significantly more willing than the patients to share personal medical information with medical agents not involved in direct care through HIE (see Table 2).

The expressed intention to use HIE for sharing personal medical information was pretty high, with significant differences between groups $(F=9.825 ; P<.001)$, Again, the source of the difference as revealed by post hoc Scheffe test was that the contact nurses were significantly more in favor of using HIE for sharing personal medical information than internal ward nurses or the patient group.

Multivariate linear regressions were performed to examine the variables predicting the readiness to share information on HIE with medical healthcare providers, medical agents not involved in direct care and the intention to use HIE. The variables entered into the model were religion (Jewish/not Jewish), role (nurse vs. patients and contact nurses vs. hospital nurses and patients), attitudes, and knowledge. 
Table 3

Linear Regression Analysis to predict the intention to use HIE or the readiness to share information on HIE with medical or non-medical staff

\begin{tabular}{|c|c|c|c|c|c|c|c|c|c|}
\hline & \multicolumn{3}{|c|}{ Intention to use HIE } & \multicolumn{6}{|c|}{ Readiness to share information on HIE with: } \\
\hline & \multirow[b]{2}{*}{$\mathrm{B}$} & \multirow[b]{2}{*}{ SE } & \multirow[b]{2}{*}{$\beta$} & \multicolumn{3}{|c|}{ Medical Staff } & \multicolumn{3}{|c|}{ Non Medical Staff } \\
\hline & & & & B & SE & $\beta$ & $\mathrm{B}$ & SE & $\beta$ \\
\hline Religion* & .515 & .329 & .067 & .223 & .130 & .075 & -.008 & .143 & -.003 \\
\hline${ }_{\mathrm{P}}^{\# C N \text { vs. IN \& }}$ & .340 & .400 & .040 & .122 & .157 & .038 & -.187 & .172 & -.055 \\
\hline$\# \# N$ vs. $P$ & .731 & .279 & $.128 * *$ & .494 & .110 & $.227 * \star \star$ & .731 & .279 & $.128^{\star \star \star}$ \\
\hline Knowledge & -.009 & .029 & -.012 & -0.44 & 0.012 & $-.156^{\star \star \star}$ & -.054 & .013 & 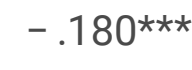 \\
\hline \multirow[t]{3}{*}{ Attitudes } & 2.276 & .177 & $.515^{\star \star \star}$ & .674 & .070 & $.403^{* \star *}$ & .629 & .076 & $.358 * \star \star$ \\
\hline & \multicolumn{3}{|c|}{$\mathrm{R}^{2}=29.8 \%$} & \multicolumn{3}{|c|}{$\mathrm{R}^{2}=23.4 \%$} & \multicolumn{3}{|c|}{$\mathrm{R}^{2}=16.4 \%$} \\
\hline & \multicolumn{3}{|c|}{$F=40.73^{\star \star \star}$} & \multicolumn{3}{|c|}{$F=29.915^{\star \star \star}$} & \multicolumn{3}{|c|}{$F=19.653^{\star \star \star}$} \\
\hline \multicolumn{10}{|c|}{$\star \star P<.01 * \star \star P<.001$} \\
\hline \multicolumn{10}{|c|}{$\mathrm{CN}=$ Contact Nurses; $\mathrm{IN}=$ Internal Ward Nurses; $\mathrm{P}=$ patients; $\mathrm{N}=$ Nurses } \\
\hline
\end{tabular}

Table 3 shows that a positive attitude, less knowledge, and being a nurse (both groups) were associated with more readiness to share information with both healthcare providers and with medical agents not involved in direct care, as well as with more intention to use HIE.

\section{Discussion}

The current study revealed a low level of knowledge about HIE among hospital and community nurses, as well as among hospitalized patients with a chronic illness. Despite this low level of knowledge, both nurses and patients held a positive attitude toward HIE. This confirms the strong public support for HIE that has been reported previously, and is probably the result of a perception that it will improve treatment and care, even though security and privacy concerns have consistently been seen as major barriers [14, $20,21]$. The higher willingness of all participants in the current study to share personal medical information with health care workers (such as nurses and physicians), rather than with medical agents not involved in direct care, such as pharmacists, might reflect such concerns. In this context, Sittig et al highlighted the shared responsibly of government regulators, and national and international policymakers, for health information technology safety [22]. Interestingly, both groups of nurses in the current study (contact and internal wards) were more willing than the patients to share information with medical agents not involved in direct care. This finding can be explained by the standards on which the 
nursing clinical decision making process is based, with respect to effective communication, knowledge sharing, and information sharing with multidisciplinary teams $[23,24]$.

Interestingly, contact nurses held the most positive attitudes towards HIE, were more willing to share information with health care workers through HIE, and had a significantly higher intention to use HIE than the other two groups. Contact nurses in the community are responsible for coordinating the continuation of home care of people with chronic illness after hospital discharge. In an aging population, the number of chronically ill patients increases, hospital stays shorten, and the quantity of hospital beds decreases, making information exchange very relevant for discharge planning and home care [25]. Hence, as the main professionals involved in the process of discharge, community nurses need to cooperate with health and non-health professionals in order to develop, improve, and redesign community services [26]. $\mathrm{HIE}$ is therefore perceived by these nurses as favorable, applicable, and a valuable resource to facilitate their work.

Being a nurse (regardless of role i.e. contact nurse or internal ward nurse) was connected in the current study to a greater intention to use HIE. Nurses are aware of the part they play in updating and integrating medical information into technology systems ${ }^{26}$, and frequently encounter difficulties associated with missing data [3]. For example, medical staff in hospitals require information about the medication that patients receive at home. Even though the patient's report is not always reliable, in the present reality, it may be the only source of information. The nurses therefore appreciate that if HIE was in use, this information would be available and accurate.

The literature reveals that like Israel, many other countries face challenges raised by the implementation of the HIE system. A systematic review of studies conducted in the US determined that although the use of HIE by health teams is increasing, the extent of use is still limited [5]. The results of this study are in accordance with a recent review that included studies from the USA, France, Sweden, Canada, New Zealand and South Korea and concluded that in order to enhance the adoption of HIE, policy makers should emphasize the HIE benefits to patients, and address their concerns [13]. Importantly, our present results indicated that positive attitudes towards HIE predicted more intention to use the system. Hence, in order to promote the assimilation of HIE by caregivers and increase the acceptance by patients, policy makers should target the attitudes of potential users and provide them with information that will emphasize the advantages of the system.

This process is necessary since the results of this study indicate that the introduction of the planned HIE system is likely to elicit objection and fear. A similar response was seen when a biometric ID system was launched in Israel about a year ago. In this case, the initiative had taken several years to implement because of an activist objection campaign that scared the public and delayed the application for several years [28]. We recommend that in order to minimize objection to the introduction of HIE systems, the public's knowledge gap must be filled by a campaign emphasizing the advantages of HIE.

\section{Limitations}

Page 12/16 
The current study did not examine the types of chronic illnesses or the health status of the patients surveyed, both of which, may affect the study's findings. Data were collected in only two hospitals, which could have influenced the attitudes or readiness to share health information of both the nurses and the patients. However, the large sample and that contact nurses who experience the difficulties of retaining the continuity of care were most positive and the differences found between research groups hint to reliability of the results. Nonetheless, a follow-up study should take into account the characteristics of the patients together with the location of the hospital site, and the nurses' work environment.

\section{Conclusions}

Worldwide integration of HIE into hospitals and communities is a challenging task [1] and depends on public support [29]. There are many obstacles that must be taken into consideration before integrating $\mathrm{HIE}$ and these include the opinions of the public and health care providers. Resources should be allocated to develop methods of documentation and preservation of medical information at all endpoints in an effective and secure manner. In addition, it is necessary to explain the HIE system and disseminate relevant information to the public as well as to healthcare teams. Conferences highlighting the clinical, organizational, and financial benefits of HIE should be held for the benefit of healthcare organizations [21]. We recommend policy makers to organize a national campaign under the auspices of the Ministry of Health, in order to present the advantages of HIE provide informed knowledge and refute misconceptions.

\section{Abbreviations}

HIE: Health Information Exchange, HITECH: Health Information Technology for Economics and Clinical Health, HMO: Health Maintenance Organizations, ANOVA: Analysis of variance, SD; standard deviation, CN: Contact Nurses, IN: Internal Ward Nurses, P: patients; N: Nurses.

\section{Declarations}

\section{Ethics approval and consent to participate}

The study was approved by: a. the Helsinki committees of the two hospitals where data were collected (2958-16-SMC, Sheba Medical Center: and 0033-16-MMC, Meir Medical Center); b. the Helsinki committee of the HMO (bb0023/16, Maccabi Health Services); c. the ethics committee of Tel-Aviv University (01062016). Prior to questionnaire completion, all participants received a short explanation about the aims of the study and were promised confidentiality, after they gave their verbal consent to participate in the study.

\section{Consent for publication}

Not applicable.

\section{Availability of data and materials}


All data generated or analyzed during this study are included in this published article. The datasets during and/or analyzed during the current study available from the corresponding author on reasonable request.

\section{Competing interests}

The authors declare that they have no competing interests.

\section{Funding}

This study was supported by the Israeli National Institute for Health Policy Research (grant number: $r / 100 / 2015)$. The funding offices had no direct or indirect involvement in the study write-up and analysis, it was only involved in budgeting and budget evaluation.

\section{Authors' contributions}

MI and SB: Conceptualization and study planning, construction of questionnaires, data analysis, writing and reviewing manuscript, and approval of final manuscript for publication.

EK, KAH, LL, IG: Construction of questionnaires, data collection, approval of final manuscript for publication.

\section{Acknowledgments}

The authors would like to thank the patients and nurses who participated at this study.

\section{References}

1. Kash BA, Baek J, Davis E, et al. 2nd. Review of successful hospital readmission reduction strategies and the role of health information exchange. Int J Med Inform. 2017;104:97-104. doi:10.1016/j.ijmedinf.2017.05.012. PubMed PMID: 28599821. Epub 2017/06/11.

2. Goldstein MM. Health information privacy and health information technology in the US correctional setting. Am J Public Health. 2014;104(5):803-9. doi:10.2105/ajph.2013.301845. PubMed PMID: 24625160; PubMed Central PMCID: PMCPMC3987588. Epub 2014/03/15.

3. Thorn SA, Carter MA. The potential of health information exchange to assist emergency nurses. $J$ Emerg Nurs. 2013;39(5):e91-6. doi:10.1016/j.jen.2012.12.007. PubMed PMID: 23369772. Epub 2013/02/02.

4. Parker $C$, Reeves $M$, Weiner $M$, et al. Health information exchange organizations and their support for research: Current state and future outlook. Inquiry:. 2017;54:0046958017713709.

5. Devine EB, Totten AM, Gorman P, et al. Health Information Exchange Use (1990-2015): A Systematic Review. EGEMS (Wash DC). 2017;5(1):27. PubMed PMID: 29881743; PubMed Central PMCID: PMCPMC5983051. 
6. Cunningham WE, Ford CL, Kinsler JJ, et al. Effects of a laboratory health information exchange intervention on antiretroviral therapy use, viral suppression, and racial/ethnic disparities. J Acquir Immune Defic Syndr. 2017;75(3):290-8.

7. Eden KB, Totten AM, Kassakian SZ, et al. Barriers and facilitators to exchanging health information: a systematic review. Int J Med Inform. 2016;88:44-51. PubMed PMID: 26878761; PubMed Central PMCID: PMCPMC4778080.

8. Codagnone C, Lupiañez-Villanueva F. Benchmarking Deployment of eHealth among General Practitioners (2013) - Final Report. Lukembourg: European Commission; 2013.

9. Schoen C, Osborn R, Squires D, et al. A survey of primary care doctors in ten countries shows progress in use of health information technology, less in other areas. Health Aff (Millwood). 2012;31(12):2805-16. PMID: 23154997.

10. Israeli Ministry of Health. Health Information Exchange in Israel.. 2014. [URL: https://www.health.gov.il/hozer/mk05_2014.pdf] (Hebrew).

11. Israeli Ministry of Health. Eitan - Medical information sharing.. 2019. [URL: https://www.health.gov.il/Subjects/DigitalHealth/Activity/Projects/Pages/OfekEitan.aspx] (Hebrew).

12. Israeli Ministry of Health. Medical information sharing.. 2019. [URL: https://www.health.gov.il/About/projects/shared_medical_info/Pages/default.aspx.] (Hebrew).

13. Esmaeilzadeh $P$, Sambasivan M. Patients' support for health information exchange: a literature review and classification of key factors. BMC Med Inform Decis Mak. 2017;17(1):33.

14. Medford-Davis LN, Chang L, Rhodes KV. Health Information Exchange: What do patients want? Health Informatics J. 2017;23(4):268-78. Epub 2016/06/02. doi: 10.1177/1460458216647190. PubMed PMID: 27245671.

15. Wright A, Soran $C$, Jenter $C A$, et al. Physician attitudes toward health information exchange: results of a statewide survey. J Am Med Inform Assoc. 2010;17(1):66-70. PubMed PMID: 20064804; PubMed Central PMCID: PMCPMC2995629.

16. Vest JR, Jasperson S. How are health professionals using health information exchange systems? Measuring usage for evaluation and system improvement. J Med Syst. 2012;36(5):3195-204. PubMed PMID: 22127521; PubMed Central PMCID: PMCPMC3402621.

17. Faul F, Erdfelder E, Buchner A, et al. Statistical power analyses using $G *$ Power 3.1: Tests for correlation and regression analyses. Behav Res Methods. 2009;41(4):1149-60. doi:10.3758/BRM.41.4.1149. PubMed PMID: 19897823.

18. Whiddett R, Hunter I, Engelbrecht $\mathrm{J}$, et al. Patients' attitudes towards sharing their health information. Int J Med Inform. 2006;75(7):530-41. doi:10.1016/j.ijmedinf.2005.08.009. PubMed PMID: 16198142. Epub 2005/10/04.

19. Johnson KB, Unertl KM, Chen Q, et al. Health information exchange usage in emergency departments and clinics: the who, what, and why. J Am Med Inform Assoc. 2011;18(5):690-7. PubMed PMID: 21846788; PubMed Central PMCID: PMCPMC3168326. 
20. Ancker JS, Edwards AM, Miller MC, et al. Consumer perceptions of electronic health information exchange. Am J Prev Med. 2012;43(1):76-80. doi:10.1016/j.amepre.2012.02.027. PubMed PMID: 22704751. Epub 2012/06/19.

21. Esmaeilzadeh P, Sambasivan M. Health Information Exchange (HIE): A literature review, assimilation pattern and a proposed classification for a new policy approach. J Biomed Inform. 2016;64:74-86. doi:10.1016/j.jbi.2016.09.011. PubMed PMID: 27645322. Epub 2016/09/21.

22. Sittig DF, Belmont $E$, Singh $H$. Improving the safety of health information technology requires shared responsibility: It is time we all step up. Healthc (Amst). 2018;6(1):7-12. doi:10.1016/j.hjdsi.2017.06.004. PubMed PMID: 28716376. Epub 2017/07/19.

23. Lawn S, Delany T, Sweet L, Battersby M, Skinner T. Barriers and enablers to good communication and information-sharing practices in care planning for chronic condition management. Aust J Prim Health. 2015;21(1):84-9. doi:10.1071/py13087. PubMed PMID: 24176299. Epub 2013/11/02.

24. Int Nurs Rev 2019;"66(2):234-241. Epub 2019/02/12. doi: 10.1111/inr.12488. PubMed PMID: 30740677.

25. Nordmark S, Soderberg S, Skar L. Information exchange between registered nurses and district nurses during the discharge planning process: cross-sectional analysis of survey data. Inform Health Soc Care. 2015;40(1):23-44. doi:10.3109/17538157.2013.872110. PubMed PMID: 24393036. Epub 2014/01/08.

26. Barrett A, Terry DR, Le Q, et al. Factors influencing community nursing roles and health service provision in rural areas: a review of literature. Contemp Nurse. 2016;52(1):119-35. PubMed PMID: 27264878.

27. Campbell ML, Rankin JM. Nurses and electronic health records in a Canadian hospital: examining the social organisation and programmed use of digitised nursing knowledge. Sociol Health Illn. 2017;39(3):365-79. PubMed PMID: 27726159.

28. No to a Biometric Database. [URL: http://english.no2bio.org/.].

29. Ancker JS, Kern LM, Abramson E, et al. The Triangle Model for evaluating the effect of health information technology on healthcare quality and safety. J Am Med Inform Assoc. 2012;19(1):61-5. PubMed PMID: 21857023; PubMed Central PMCID: PMCPMC3240765.

\section{Supplementary Files}

This is a list of supplementary files associated with this preprint. Click to download.

- STROBEchecklistcrosssectional.docx

- QuestionnairePatientsandNurses.docx 